\title{
Neural Activity to a Partner's Facial Expression Predicts Self-Regulation After Conflict
}

\section{Citation}

Hooker, Christine I., Anett Gyurak, Sara C. Verosky, Asako Miyakawa, and Özlem Ayduk. 2010. "Neural Activity to a Partner's Facial Expression Predicts Self-Regulation After Conflict." Biological Psychiatry 67 (5) (March): 406-413. doi:10.1016/j.biopsych.2009.10.014.

\section{Published Version}

10.1016/j.biopsych.2009.10.014

\section{Permanent link}

http://nrs.harvard.edu/urn-3:HUL.InstRepos:17497807

\section{Terms of Use}

This article was downloaded from Harvard University's DASH repository, and is made available under the terms and conditions applicable to Other Posted Material, as set forth at http:// nrs.harvard.edu/urn-3:HUL.InstRepos:dash.current.terms-of-use\#LAA

\section{Share Your Story}

The Harvard community has made this article openly available.

Please share how this access benefits you. Submit a story.

\section{Accessibility}




\title{
Neural activity to a partner's facial expression predicts self- regulation after conflict
}

\author{
Christine I. Hooker ${ }^{1}$, Anett Gyurak ${ }^{2}$, Sara Verosky ${ }^{3}$, Asako Miyakawa ${ }^{3}$, and Özlem Ayduk ${ }^{2}$ \\ ${ }^{1}$ Harvard University, Psychology Department \\ 2University of California at Berkeley, Psychology Department \\ ${ }^{3}$ University of California at Berkeley, Helen Wills Neuroscience Institute
}

\section{Abstract}

Introduction-Failure to self-regulate after an interpersonal conflict can result in persistent negative mood and maladaptive behaviors. Research indicates that lateral prefrontal cortex (LPFC) activity is related to the regulation of emotional experience in response to lab-based affective challenges, such as viewing emotional pictures. This suggests that compromised LPFC function may be a risk-factor for mood and behavior problems after an interpersonal stressor. However, it remains unclear whether LPFC activity to a lab-based affective challenge predicts self-regulation in real-life.

Method-We investigated whether LPFC activity to a lab-based affective challenge (negative facial expressions of a partner) predicts self-regulation after a real-life affective challenge (interpersonal conflict). During an fMRI scan, healthy, adult participants in committed, dating relationships $(N=27)$ viewed positive, negative, and neutral facial expressions of their partners. In an online daily-diary, participants reported conflict occurrence, level of negative mood, rumination, and substance-use.

Results-LPFC activity in response to the lab-based affective challenge predicted self-regulation after an interpersonal conflict in daily life. When there was no interpersonal conflict, LPFC activity was not related to the change in mood or behavior the next day. However, when an interpersonal conflict did occur, ventral LPFC (VLPFC) activity predicted the change in mood and behavior the next day, such that lower VLPFC activity was related to higher levels of negative mood, rumination, and substance-use.

Conclusions-Low LPFC function may be a vulnerability and high LPFC function may be a protective factor for the development of mood and behavior problems after an interpersonal stressor.

Interpersonal conflicts are emotionally challenging, not only because conflicts provoke negative affect in the moment but also because, once provoked, negative affect must be managed effectively in order to motivate adaptive behavior in the conflict's aftermath(1). Failure to regulate mood and behavior after experiencing a negative event, such as

C 2009 Society of Biological Psychiatry. Published by Elsevier Inc. All rights reserved Contact Information: Christine Hooker, Ph.D. William James Hall 820, Psychology Department Harvard University 33 Kirkland St. Cambridge, MA 02138 Office Phone: 617-496-7095 Cell Phone: 510-289-1102 chooker@wjh.harvard.edu.

Publisher's Disclaimer: This is a PDF file of an unedited manuscript that has been accepted for publication. As a service to our customers we are providing this early version of the manuscript. The manuscript will undergo copyediting, typesetting, and review of the resulting proof before it is published in its final citable form. Please note that during the production process errors may be discovered which could affect the content, and all legal disclaimers that apply to the journal pertain. 
interpersonal conflict, can result in persistent negative mood and potentially self-destructive responses. These maladaptive responses, such as rumination or substance-use, can trigger a downward spiral that ultimately impairs functioning(2-6).

Self-regulation, including regulation of emotion and behavior, is achieved through a variety of strategies that use cognitive skills, such as interpretation, attention, and inhibition, to modulate one's experience and reactions(7). It is well established that these cognitive skills are mediated by a network of neural regions in which the lateral prefrontal cortex (LPFC) is a key component(8). Recent research shows that the LPFC, particularly the ventral portion (VLPFC), facilitates emotion regulation by influencing the temporal course and intensity of emotional experience through strategies that rely on cognitive skills - specifically, evaluation, affect labeling, attentional control, and reappraisal(9-13) When implementing these strategies to control emotion, people with greater LPFC activity in response to stimuli provoking negative affect, such as gruesome images and physical pain $(10-12,14)$ report less distress resulting from those stimuli. Greater LPFC activity to emotional stimuli is also related to better impulse control(15). These data support the idea that the LPFC implements control-related mechanisms to down-regulate negative affect and inhibit maladaptive behaviors.

Furthermore, dysfunction in the LPFC has been observed in multiple psychiatric disorders, such as unipolar and bipolar mood disorders(16-18), borderline personality disorder(19,20), and substance abuse(5), which are characterized by the inability to regulate negative affect and maladaptive behaviors. Symptoms of these disorders can be precipitated or exacerbated by an interpersonal conflict with a partner(21). Thus, it has been proposed that LPFC dysfunction may be a biological vulnerability, or diathesis, that interacts with a stressor, such as an interpersonal conflict, to produce problematic mood and behavioral $\operatorname{symptoms}(16,21)$.

Prior research investigating the role of LPFC in regulating emotional response has used labbased affective challenges, such as negative pictures, as an approximation of real-life affective challenges. However no research thus far has addressed whether LFPC activation to a lab-based affective challenge predicts self-regulation in response to a real-life affective challenge. Furthermore, the exact mechanism regarding how an LPFC diathesis interacts with a stressful event, such as interpersonal conflict, is unclear. People in a negative mood state or who have a dispositional propensity to feel negative mood (as measured by high levels of neuroticism) may be more sensitive to negative interpersonal cues(22,23), making it difficult to determine whether maladaptive response to interpersonal conflict is the result of increased sensitivity to negative information or failure to recruit effective self-regulation strategies(7).

To investigate the basic mechanism of this diathesis-stress model, we address these questions with healthy participants involved in romantic relationships. We used fMRI along with behavioral tasks and a daily-diary study to test whether LPFC neural response to a labbased affective challenge would predict regulation of mood and behavior in response to a real-life affective challenge - an interpersonal conflict with a partner. Negative facial expressions from the partner served as the lab-based affective challenge, a stimulus designed to elicit control-related LPFC activity. Participants also completed a structured diary questionnaire to assess daily conflicts, mood, and maladaptive behaviors over a 3-week period. We tracked the change in mood and maladaptive behaviors from the day of the conflict to the day after. We then tested whether the LPFC activity from the lab-based affective challenge predicted the change in mood and maladaptive behaviors. We predicted that although everyone would experience an increase in negative mood on the day of interpersonal conflict, recovery from this negative event by the following day would depend 
on LPFC function. These methods address concerns of the previous literature by accounting for immediate response to conflict and directly addressing the role of subsequent regulatory ability. To validate that LPFC activity in response to the lab-based affective challenge relied on cognitive skills, we correlated LPFC neural activity with performance on traditional measures of cognitive control capacity.

\section{MATERIALS AND METHODS}

\section{Participants}

Couples in dating relationships for at least 3 months were recruited. Twenty-seven (13M/ 14F) English speaking, right-handed adults participated in the study [Mean age $=21$ years $(S D=2.4)$; mean relationship length 22.4 (20.01) months]. Participants included 11 couples and 5 individuals whose partners did not undergo fMRI scanningi. They reported no neurological or psychiatric illness and were not taking psychotropic medication.

\section{Procedure}

At the initial lab session each participant completed questionnaires assessing relationship closeness(24), relationship commitment, and trait neuroticism(25) as well as 3 standard measures of cognitive-control capacity: 1) a behavioral "Go/No-Go" task to assess response inhibition(26); and self-report questionnaires of 2) voluntary attentional control(27) and 3) behavioral impulsivity (28). They also had facial expression photographs taken, were screened for the fMRI study, scheduled for a scan, if eligible, and received instructions on the structured daily-diary questionnaires.

The behavioral and self-report measures are standard instruments (see Supplement 1) and were used here to better understand our primary fMRI and daily-diary results.

\section{fMRI Task}

Subjects viewed pictures of their partner, themselves, and an opposite-sex stranger in three facial expression conditions: negative, positive, and neutral. Data from the partner and opposite-sex stranger are reported here ${ }^{\mathrm{ii}}$.

Facial Expression Stimuli: Photographs were taken of each participant posing interpersonally meaningful facial expressions, including four negative expressions (anger, disappointment, contempt, and disgust), four positive expressions (happy, flirty, caring, and pleasantly-surprised), and a neutral expression. Expressions were coached by showing the participant model expressions from standardized facial affect stimulus sets $(29,30)$. One female served as the Stranger for male participants and one male served as the Stranger for female participantsiii.

During the fMRI scan, participants rated how each picture made them feel on a scale ranging from 1 (very negative) to 4 (very positive). Purposefully, there were no explicit instructions to regulate emotional reactions, thus allowing for individual differences in the amount of control applied in response to the affective challenge.

\footnotetext{
${ }^{i}$ Although heterosexuality was not specified in recruitment, all couples in the sample were heterosexual.

ii Post-scan ratings of the photo stimuli showed that participants were significantly more embarrassed when viewing pictures of themselves as compared to pictures of their partner or the stranger. Because feelings of embarrassment presented a potentially confounding factor, the Self trials were dropped from further analysis.

iii The Stranger photographs were selected by research staff based on the quality of the photograph, such as how well the target emotions were depicted.
} 
The partner's negative facial expression condition was the lab-based affective challenge. Neural activity in response to Partner Negative versus Partner Neutral expressions was expected to be the strongest predictor of self-regulation after conflict. Additional conditions of positive valence and an opposite-sex stranger were included to identify whether the predictive value of the lab-based affective challenge was specific to negatively valenced or personally meaningful stimuli.

\section{fMRI Task}

Photographs were presented in blocks of 12 pictures from each condition ( 3 pictures from each specific emotion). Each picture was presented for $2 \mathrm{~s}$. Each $24 \mathrm{~s}$ condition block was followed by 12 seconds of "rest." Each condition block was repeated 9 times in a fixed random order across 3 runs. There were six conditions of interest: Partner Negative, Partner Positive, Partner Neutral, Stranger Negative, Stranger Positive, and Stranger Neutral.

\section{fMRI Image Acquisition, Processing and Analysis}

Images were acquired on a 4T Varian INOVA scanner. See Supplement 1 for acquisition and processing details.

For each contrast of interest, significant activation $t(26)=3.4, p<.001$ (uncorrected) at the group level was corrected for multiple comparisons within the LPFC (Figure 1). Individual participant's level of neural activity from each significant LPFC cluster was extracted and used as a predictor in the hierarchical linear modeling analysis with the daily-diary data.

\section{Reports of Mood and Behavior in the Daily-Diary}

The online daily-diary consisted of structured questionnaires completed at the end of each day (between 5PM and 3AM) for 21 days. Participants were asked to complete the diary separately from their partner and refrain from discussing their responses until the study ended. Electronic questionnaire submissions were time stamped and could not be modified. Each day participants reported whether or not they had a conflict with their partner (yes/no), and rated ( 5 point scale: $1=$ not at all; $5=$ extremely) the extent to which the conflict was resolved, the extent to which they felt positive and negative mood, and engaged in rumination, and substance-use.

The specific items were as follows: Positive mood: "loved," "accepted," "happy," "calm," "supported," "satisfied," "confident." Negative mood: "insecure," "self-critical," "resentful," "guilty," "ashamed," "anxious," “angry," "lonely," "rejected," "depressed," "suspicious." Rumination: "I replayed an argument I had with my partner in the past over and over in my head." Substance-use: "I drank alcohol or used drugs more than I should have." Conflict resolution: "The conflict has been resolved to my satisfaction."

\section{Analysis of Neural Activity and Daily-Diary Data}

The diary data involved a hierarchical structure where participants were nested within couples, and days of assessment were nested within participants. For each couple, this structure represented a two-level model and required the simultaneous analysis of withinperson and between-person levels that are hierarchically organized.

Mixed procedure in SAS statistical package (SAS Institute, Cary, NC)(31) was used to estimate within-subjects associations between occurrence of a conflict on any given diary day, and mood and behavior the next day. We identified longitudinal changes in mood and behavior from conflict days to the following day. To examine whether the effect of conflict on next day's mood and behavior was dependent on between-subjects differences in LPFC activity, we tested the statistical interaction between conflict occurrence and LPFC activity 
by using contrast values extracted from significant LPFC clusters. Our hypothesis was that on days preceded by conflict, low LPFC activity would be related to higher levels of overall negative mood, rumination, and substance-use. Following days when no conflict occurred we did not expect LPFC activity to be significantly related to mood and behavior the next day. (See Supplement 1).

All analyses controlled for neuroticism to ensure that individual differences in the neural response to negative facial expressions(22) or the propensity to experience negative mood(32) did not influence the results. Big Five Inventory(25) mean neuroticism [7 point scale(2)] was 3.9 (1.2) with range 1.9-6.1.

\section{RESULTS}

\section{Behavioral Results from fMRI Scan}

Participants reported more negative feelings in response to negative versus neutral expressions and more positive feelings in response to positive versus neutral expressions in both the partner and stranger conditions (Table 1). These findings indicate that the facial expression stimuli produced the expected affective response.

\section{fMRI Results}

Results from the group analysis shows that the LPFC was significantly more active to negative and positive expressions as compared to neutral expressions from the partner and the stranger (Table 2). Activation in each contrast was in the VLPFC, with peak activation in the inferior frontal gyrus - triangularis region (BA45).

\section{Behavioral Results from the Daily Diary}

Eighty-five percent of the group (23 participants) reported at least one conflict with their partner during the diary period. Across all participants, the number of conflict days ranged from $0-8$; the average number of conflict days was $X=2.11$ (2.22), representing approximately $10 \%$ of the 21 diary days. Couples agreed about whether a conflict had occurred on $91 \%$ of the days.

Positive mood items $(\alpha=.91)$ and negative mood items $(\alpha=.90)$ had adequate internal consistency. Across the 21 diary days, average positive mood $[\mathrm{X}=3.35(.76)]$ and negative mood $[\mathrm{X}=1.51(.55)]$ at the daily level were negatively related to one another $(b=-.40, p=$. 0001). Therefore, positive mood items were reverse scored to create a single overall negative mood index where higher scores indicated greater negative mood and lower positive mood $[X=1.95(.53)]$. Across the 21 diary days, the average level of rumination was $X=1.2$ (.66), substance-use was $X=1.1$ (.56), and conflict resolution was $X=2.56(1.38)$.

\section{Relationship between Neural Activity and Daily-Diary Data}

Individual contrast values from each LPFC cluster listed in Table 2 were extracted and entered as a predictor in the HLM ${ }^{\mathrm{iv}}$. LPFC activity from two contrasts [Partner Negative vs. Partner Neutral and Partner Positive vs. Partner Neutral] significantly interacted with interpersonal conflict to predict change in mood and/or behavior. These data are detailed below. None of the other contrasts showed a significant interaction with conflict.

\footnotetext{
${ }^{\text {iv }}$ Across the diary period, neuroticism was significantly related to mean level of negative mood $[\mathrm{r}(25)=.41, \mathrm{p}=.03]$ and shows a trend level relationship to rumination $[\mathrm{r}(25)=.36, \mathrm{p}=.06]$ and substance-use $[\mathrm{r}(25)=.35, \mathrm{p}=.07]$. These results indicate that it is appropriate to control for neuroticism (as we did) in our analyses. Neuroticism was not related to VLPFC activity.
} 


\section{Left VLPFC Activity: Partner Negative versus Partner Neutral Expressions}

In the analysis of day-to-day changes in mood and behavior, left VLPFC activity to Partner Negative vs. Partner Neutral significantly interacted with occurrence of conflicts in predicting change in overall negative mood $[F(1,15)=6.31, b=-.12, p=.02]$, rumination $[F(1,15)=6.54, b=-.25, p=.02]$, and substance-use $[F(1,15)=8.45, b=-.16, p=.01]$. To further understand these interactions, we examined the relationship between left VLPFC activity and mood and behavior for days in which no conflict occurred the previous day and then separately for days in which a conflict had occurred the previous day by conducting simple slopes analysis(33). On days when no interpersonal conflict was reported the previous day, left VLPFC activation had no relationship to any of the outcome variables [overall negative $\operatorname{mood}(b=-.02, t(15)=-.88, p=.39)$; rumination $(b=-.01, t(15)=-.34, p=$. 74); substance-use $(b=-.002, t(15)=.09, p=.93)]$.

However, on days following interpersonal conflicts, left VLPFC activity was significantly associated with overall negative $\operatorname{mood}[b=-.12, t(15)=-2.66, p=.02]$, rumination $[b=-.22$, $t(15)=-2.72, p=.02]$, and substance-use $[b=-.16, t(15)=-2.92, p=.01]$, such that participants with lower VLPFC had higher overall negative mood, more rumination, and more substance-use on days following interpersonal conflict. See Figure 2.

To further investigate the relationship between left VLPFC activity and change in overall negative mood, additional analysis were conducted on negative mood and positive mood separately. Left VLPFC activity to Partner Negative vs. Partner Neutral significantly interacted with occurrence of conflicts in predicting negative mood only $[F(1,15)=5.00, b=$ $-.14, p=.04]$ and positive mood only $[F(1,15)=6.08, b=.17, p=.03]$. In the absence of conflict, there was no relationship between left VLPFC and negative mood $[b=-.01, t(15)=$ $-.41, p=.69]$ or positive mood $[b=.01, t(15)=.45, p=.66]$ the next day. However, on days following conflict, left VLPFC activity predicted negative mood $[b=-.12, t(15)=-2.08, p=$. $05]$ and positive mood $[b=.19, t(15)=2.61, p=.02]$, such that lower left VLPFC activity was related to more negative mood and less positive mood. Thus, both positive and negative mood contributed to the mood effect.

\section{Left VLPFC Activity: Partner Positive versus Partner Neutral}

Left VLPFC activity to Partner Positive versus Partner Neutral expressions significantly interacted with the occurrence of interpersonal conflicts in predicting change in overall negative $\operatorname{mood}[F(1,15)=5.02, b=-.10, p=.04]$ but not rumination $[F(1,15)=2.39, b=-.13$, $p=.14]$ or substance-use $[F(1,15)=3.54, b=-.13, p=.08]$.

Analysis of the interaction between left VLPFC activity and conflict showed that when there was no conflict the previous day, left VLPFC activity had no relationship to overall negative mood $[b=-.004, t(15)=-.16, p=.87]$. However, left VLPFC activity predicted overall negative mood on days following an interpersonal conflict [ $t(15)=2.40, b=-.10, p=.03]$, such that people with lower VLPFC activity had more overall negative mood (see Figure 3).

Additional analyses on negative mood and positive mood separately suggest that the relationship between left VLPFC activity to Partner Positive vs. Partner Neutral and change in overall negative mood after conflict is driven, primarily, by the change in positive mood. Left VLPFC activity did not interact with occurrence of conflicts in predicting negative mood only $[F(1,15)=.25, b=-.03, p=.62]$ but it did predict positive mood only $[F(1,15)=6.5$, $b=.14, p=.02]$. In the absence of conflict, there was no relationship between left VLPFC and positive mood $[b=-.01, t(15)=-.23, p=.82]$ the next day. However, on days following conflict, left VLPFC activity predicted positive mood at the trend level $[b=.12, t(15)=1.84$, $p=.09$ ], such that lower left VLPFC activity was related to less positive mood. 
See Supplement 1 for detailed results.

\section{Validation of the Observed Relationship between Neural Activity and Daily-Diary}

Left VLPFC Activity and Reaction to Conflict-Analyses were conducted to verify that VLPFC activity was related to regulation after conflict and not reactivity to conflict. We calculated the (within person) association between conflict occurrence and the change in overall negative mood, rumination and substance-use from the day prior to conflict to the day of conflict. This showed a main effect of conflict, such that all participants had an increase in overall negative mood $[\mathrm{F}(1,15)=13.94, t(15)=3.73, b=.29, p=.001]$ and rumination $[\mathrm{F}(1,15)=17.93, t(15)=4.23, b=.66, p=.0007]$. However, left VLPFC did not interact with conflict to predict this change in negative mood or rumination [interaction terms between VLFPC activity (both contrasts) and conflict, Fs $<1$ ], showing that the increase in negative mood and rumination on the day of the conflict was not dependent on LPFC activity. There was no main effect of conflict for substance-use on conflict days $[F<1]$, so no further analysis on substance-use was conducted. These findings demonstrate that LPFC is not related to initial reactivity to interpersonal conflict (i.e. everyone had an equal increase in negative mood on conflict days).

\section{Correlation between Left VLPFC Activity and Cognitive Control Measures-} Bivariate correlations between VLPFC activity and behavioral cognitive control measures were conducted to verify that VLPFC was related to cognitive control capacity. Left VLPFC activity to Partner Negative vs. Partner Neutral was positively correlated with response inhibition accuracy on the Go/No-Go task $[r(25)=.53, p=.005]$ and negatively correlated with self-reported impulsivity $[r(25)=-.38, p=.05]$, but not attentional control $[r(25)=.21$, $p=.29]$. Left VLPFC activity to Partner Positive versus Partner Neutral was positively correlated with response inhibition accuracy at the trend level $[r(25)=.35, p=.07]$ and attentional control $[r(25)=.45, p=.02]$ but not impulsivity $[r(25)=-.14, p=.49]^{\mathrm{V}}$.

Relationship Quality Indices-To verify that the findings are not due to pre-existing differences in relationship quality between those with high and low VLPFC activity, we examined the relationship between the two VLPFC activity variables discussed above and relationship quality indices. There was no significant relationship between VLPFC activity and number of conflicts, the degree to which daily conflicts were resolved, relationship commitment, or relationship closeness (all $F_{\mathrm{s}}<1$ ).

\section{Discussion}

These results show that LPFC activity in response to a lab-based affective challenge negative facial expressions from a partner - predicts the ability to regulate mood and behavior after a real-life affective challenge - an interpersonal conflict with that person. Control-related VLPFC activity to the partner's negative facial expressions robustly predicted whether an interpersonal conflict resulted in a significant change in mood, rumination, and substance-use. Specifically, when there was no interpersonal conflict, left VLPFC activity was not related to mood or behavior the next day. However, when an interpersonal conflict did occur, left VLPFC predicted mood and behavior the next day, such that lower VLPFC activity was related to higher levels of overall negative mood, rumination, and substance-use. In addition, left VLPFC activity to the partner's positive expressions predicted overall negative mood after conflict, such that lower VLPFC activity was related to higher overall negative mood. These data support the hypothesis that LPFC

\footnotetext{
${ }^{\mathrm{V}}$ Additional HLM analyses were conducted to see whether behavioral cognitive control measures alone would predict the change in mood and behavior after conflict. None of the cognitive control measures significantly interacted with conflict to predict change in mood and behavior.
} 
dysfunction is a vulnerability for the development of mood and behavioral problems after interpersonal stressors(16) and further suggests that intact or superior VLPFC function may be a protective factor that promotes an adaptive profile of response(34).

The current findings address potential confounds in prior research and illustrate the contribution of control-related VLPFC processes in managing mood and behavior in the aftermath of an emotionally provocative event. This contribution is seen most clearly in the analysis of overall negative mood. Here, we statistically control for the tendency to experience negative mood (i.e., neuroticism), account for individual differences in daily negative mood, and verify that VLPFC activity is related to cognitive control skills. The results show that although all participants experienced an increase in negative mood the day of the conflict, recovery from this affective challenge by the following day was dependent on VLPFC function.

Additionally, the data indicate that the VLPFC may control mood by co-opting and implementing control-related cognitive skills to both down-regulate negative mood and upregulate positive mood. High left VLPFC activity to the lab-based affective challenge (partner's negative expressions) was related to better response inhibition and impulse control. Prior research has similarly shown that high VLPFC while viewing negative facial expressions is related to better impulse control(15). This suggests that the lab-based affective challenge may have elicited control-related activity in the VLPFC. Furthermore, higher VLPFC activity to the partner's positive expressions was related to better attentional control, suggesting that different types of cognitive control mechanisms may be implemented by the VLPFC to produce the desired emotion. Consistent with this, VLPFC activity during effortful regulation is related to the successful down-regulation and upregulation of affect to both negative and positive stimuli $(12,35,36)$. The current data advances this literature by showing that VLPFC activity to the lab-based affective challenge predicts both the down-regulation of negative mood and the up-regulation of positive mood after a real-life affective challenge.

The rumination and substance-use findings suggest that VLPFC function regulates internalizing and externalizing maladaptive responses which can contribute to a downward spiral of worsening mood and behavioral problems.

Rumination, an internal focus on negative mood and thoughts(37,38), exacerbates and prolongs negative mood and predicts the onset and relapse of psychological disorders after a stressful event $(4,39)$. Thus far it has been unclear whether rumination after a negative event results from poor control over negative affect, as evidenced by the association of rumination and poor performance on cognitive control tasks(40), or greater sensitivity to negative affect, as evidenced by the association of rumination with higher neuroticism(41). Here, we control for neuroticism and daily rumination, and show that although everyone had an increase in rumination the day of the conflict, higher VLPFC activity was related to a decrease in rumination the next day.

Substance-use did not uniformly increase on the day of conflict; however, lower VLPFC activity was related to more self-reported substance-use the day after conflict. This is consistent with diathesis-stress models of substance abuse which propose that stressful events trigger impulses to reduce distress and insufficient control-related LPFC function makes those impulses difficult to resist $(6,42-44)$.

Interestingly, people with high VLPFC activity had an improvement in mood and maladaptive behavior after conflict. Although adaptive regulation strategies were not measured, one interpretation is that people with high VLPFC activity used more effective cognitive strategies to reframe the interpersonal conflict as a positive experience. Consistent 
with this interpretation, prior research has shown that greater VLPFC activity in response to negative facial expressions is related to greater use of reappraisal(45) and the use of reappraisal to identify positive meaning in negative events can create an upward spiral of adaptive responding(46-48). Our findings are also consistent with evidence showing that cognitive control skills provide protection for people at elevated risk for difficulties after a negative event $(34,49,50)$.

One limitation of the current study is that all daily mood, rumination, and substance-use measures were self-report and thus subject to bias. Future research could include a more objective measure of functioning. Additionally, while the use of personalized facial expressions created an ecologically valid and thus sensitive affective challenge, it also added variability across subjects, since some participants may have been better at posing the target expressions. Future research could include standardized stimuli as the affective challenge. Finally, it is not clear whether the change in mood and behavior shown here represents a clinically significant change. Future research, particularly with clinical samples, could use symptom measures and clinical criteria to identify whether LPFC function interacts with conflict to cause clinically significant change in symptoms, functioning, and overall distress.

Nonetheless, collectively, the current findings have implications for the clinical management and treatment of multiple psychiatric disorders. Recovering psychiatric patients who experience interpersonal criticism from a partner or family member are more likely to relapse(21). Furthermore, formerly depressed patients have low LPFC activity when listening to their mother's criticism $(51,52)$. The current study with healthy participants indicates that individual level of LPFC activity to an affective challenge may provide information about that person's risk for maladaptive responses after an interpersonal stressor, which can be used to develop strategies to cope with such environmental provocations.

In summary, our findings show that control-related VLPFC activity to an interpersonally meaningful lab-based affective challenge is a crucial neurocognitive indicator of whether a real-life affective challenge - such as an interpersonal conflict - will result in a downward spiral of worsening mood and self-destructive behaviors or an upward spiral of improved mood and adaptive responses.

\section{Supplementary Material}

Refer to Web version on PubMed Central for supplementary material.

\section{Acknowledgments}

The authors wish to thank Mark D'Esposito and Robert T. Knight for support and guidance with fMRI data collection and analysis. This research was supported by National Institute of Mental Health Grants K08 MH71746 (C.I.H.) and R01 MH 0697043 (O.A.) as well as a NARSAD Yound Investigator Award (C.I.H).

\section{References}

1. Arriaga XB, Rusbult CE. Standing in my partner's shoes: Partner perspective taking and reactions to accommodative dilemmas. Personality and Social Psychology Bulletin 1998;24:927-948.

2. Ayduk O, Downey G, Kim M. Rejection sensitivity and depressive symptoms in women. Personality and Social Psychology Bulletin 2001;27:868-877.

3. Baker TB, Piper ME, McCarthy DE, Majeskie MR, Fiore MC. Addiction motivation reformulated: an affective processing model of negative reinforcement. Psychological review 2004;111:33-51. [PubMed: 14756584]

4. Nolen-Hoeksema $S$. The role of rumination in depressive disorders and mixed anxiety/depressive symptoms. Journal of abnormal psychology 2000;109:504-511. [PubMed: 11016119] 
5. Li CS, Sinha R. Inhibitory control and emotional stress regulation: neuroimaging evidence for frontal-limbic dysfunction in psycho-stimulant addiction. Neuroscience and biobehavioral reviews 2008;32:581-597. [PubMed: 18164058]

6. Sinha R. The role of stress in addiction relapse. Current psychiatry reports 2007;9:388-395. [PubMed: 17915078]

7. Ochsner KN, Gross JJ. The cognitve control of emotion. Trends in cognitive sciences 2005;9:242249. [PubMed: 15866151]

8. Miller EK, Cohen JD. An integrative theory of prefrontal cortex function. Annual review of neuroscience 2001;24:167-202.

9. Dolcos F, McCarthy G. Brain systems mediating cognitive interference by emotional distraction. J Neurosci 2006;26:2072-2079. [PubMed: 16481440]

10. Lieberman MD, Eisenberger NI, Crockett MJ, Tom SM, Pfeifer JH, Way BM. Putting feelings into words: affect labeling disrupts amygdala activity in response to affective stimuli. Psychol Sci 2007;18:421-428. [PubMed: 17576282]

11. Lieberman MD, Jarcho JM, Berman S, Naliboff BD, Suyenobu BY, Mandelkern M, et al. The neural correlates of placebo effects: a disruption account. NeuroImage 2004;22:447-455. [PubMed: 15110038]

12. Ochsner KN, Bunge SA, Gross JJ, Gabrieli JD. Rethinking feelings: an FMRI study of the cognitive regulation of emotion. Journal of cognitive neuroscience 2002;14:1215-1229. [PubMed: 12495527]

13. Satpute $\mathrm{AB}$, Lieberman MD. Integrating automatic and controlled processes into neurocognitive models of social cognition. Brain Res 2006;1079:86-97. [PubMed: 16490183]

14. Salomons TV, Johnstone T, Backonja MM, Shackman AJ, Davidson RJ. Individual differences in the effects of perceived controllability on pain perception: critical role of the prefrontal cortex. Journal of cognitive neuroscience 2007;19:993-1003. [PubMed: 17536969]

15. Brown SM, Manuck SB, Flory JD, Hariri AR. Neural basis of individual differences in impulsivity: contributions of corticolimbic circuits for behavioral arousal and control. Emotion (Washington, DC 2006;6:239-245.

16. Davidson RJ, Pizzagalli D, Nitschke JB, Putnam K. Depression: perspectives from affective neuroscience. Annu Rev Psychol 2002;53:545-574. [PubMed: 11752496]

17. Green MJ, Cahill CM, Malhi GS. The cognitive and neurophysiological basis of emotion dysregulation in bipolar disorder. Journal of affective disorders 2007;103:29-42. [PubMed: 17328959]

18. Stanfield AC, Moorhead TW, Job DE, McKirdy J, Sussmann JE, Hall J, et al. Structural abnormalities of ventrolateral and orbitofrontal cortex in patients with familial bipolar disorder. Bipolar disorders 2009;11:135-144. [PubMed: 19267696]

19. Koenigsberg HW, Siever LJ, Lee H, Pizzarello S, New AS, Goodman M. Neural correlates of emotion processing in borderline personality disorder. Psychiatry research 2009;172:192-199. [PubMed: 19394205]

20. Lis E, Greenfield B, Henry M, Guile JM, Dougherty G. Neuroimaging and genetics of borderline personality disorder: a review. J Psychiatry Neurosci 2007;32:162-173. [PubMed: 17476363]

21. Hooley JM. Expressed emotion and relapse of psychopathology. Annual review of clinical psychology 2007;3:329-352.

22. Hooker CI, Verosky SC, Miyakawa A, Knight RT, D'Esposito M. The influence of personality on neural mechanisms of observational fear and reward learning. Neuropsychologia 2008;46:27092724. [PubMed: 18573512]

23. Gotlib IH, Krasnoperova E, Yue DN, Joormann J. Attentional biases for negative interpersonal stimuli in clinical depression. Journal of abnormal psychology 2004;113:121-135. [PubMed: 14992665]

24. Aron A, Aron EN, Smollan D. Inclusion of Other in the Self Scale and the structure of interpersonal closeness. Journal of personality and social psychology 1992;63:596-612.

25. John, OP.; Srivastava, S. The Big Five trait taxonomy: History, measurement, and theoretical perspectives. In: John, OP.; Pervin, LA., editors. Handbook of personality: Theory and research. 2nd ed.. Guilford; New York: 1999. p. 102-138. 
26. Durston S, Thomas KM, Worden MS, Yang Y, Casey BJ. The effect of preceding context on inhibition: an event-related fMRI study. NeuroImage 2002;16:449-453. [PubMed: 12030830]

27. Derryberry D, Reed MA. Anxiety-related attentional biases and their regulation by attentional control. Journal of abnormal psychology 2002;111:225-236. [PubMed: 12003445]

28. Patton JH, Stanford MS, Barratt ES. Factor structure of the Barratt impulsiveness scale. Journal of clinical psychology 1995;51:768-774. [PubMed: 8778124]

29. Baron-Cohen, S. Mind Reading Emotions Library. Jessica Kingsley Publishers Ltd; University of Cambridge, UK: 2004.

30. Ekman, P.; Matsumoto, D. Japanese and Caucasian Facial Expressions of Emotion (JACFEE). San Francisco, CA: 1993.

31. Kenny, DA.; Kashy, DA.; Cook, WL. Dyadic data analysis. Guilford Press; New York: 2006.

32. Costa PT Jr. McCrae RR. Influence of extraversion and neuroticism on subjective well-being: happy and unhappy people. Journal of personality and social psychology 1980;38:668-678. [PubMed: 7381680]

33. Aiken, LS.; West, SG. Multiple regression: Testing and interpreting interactions. Sage Publications, Inc.; Thousand Oaks, CA, US: 1991.

34. Nigg J, Nikolas M, Friderici K, Park L, Zucker RA. Genotype and neuropsychological response inhibition as resilience promoters for attention-deficit/hyperactivity disorder, oppositional defiant disorder, and conduct disorder under conditions of psychosocial adversity. Development and psychopathology 2007;19:767-786. [PubMed: 17705902]

35. Kim SH, Hamann S. Neural correlates of positive and negative emotion regulation. Journal of cognitive neuroscience 2007;19:776-798. [PubMed: 17488204]

36. Ochsner KN, Ray RD, Cooper JC, Robertson ER, Chopra S, Gabrieli JD, et al. For better or for worse: neural systems supporting the cognitive down- and up-regulation of negative emotion. NeuroImage 2004;23:483-499. [PubMed: 15488398]

37. Just N, Alloy LB. The response styles theory of depression: tests and an extension of the theory. Journal of abnormal psychology 1997;106:221-229. [PubMed: 9131842]

38. Moberly NJ, Watkins ER. Ruminative self-focus and negative affect: an experience sampling study. Journal of abnormal psychology 2008;117:314-323. [PubMed: 18489207]

39. Lyubomirsky S, Nolen-Hoeksema S. Self-perpetuating properties of dysphoric rumination. Journal of personality and social psychology 1993;65:339-349. [PubMed: 8366423]

40. Davis RN, Nolen-Hoeksema S. Cognitive inflexibility among ruminators and nonruminators. Cognitive Therapy and Research 2000;24:699-711.

41. Roberts JE, Gilboa E, Gotlib IH. Ruminative response style and vulnerability to episodes of dysphoria: gender, neuroticism, and episode duration. Cognitive Therapy and Research 1998;22:401-423.

42. Garavan H, Hester R. The role of cognitive control in cocaine dependence. Neuropsychology review 2007;17:337-345. [PubMed: 17680368]

43. Cox WM, Hogan LM, Kristian MR, Race JH. Alcohol attentional bias as a predictor of alcohol abusers' treatment outcome. Drug Alcohol Depend 2002;68:237-243. [PubMed: 12393218]

44. Goldstein RZ, Volkow ND. Drug addiction and its underlying neurobiological basis: neuroimaging evidence for the involvement of the frontal cortex. The American journal of psychiatry 2002;159:1642-1652. [PubMed: 12359667]

45. Drabant EM, McRae K, Manuck SB, Hariri AR, Gross JJ. Individual differences in typical reappraisal use predict amygdala and prefrontal responses. Biological psychiatry 2009;65:367373. [PubMed: 18930182]

46. Campbell L, Simpson JA, Boldry J, Kashy DA. Perceptions of conflict and support in romantic relationships: The role of attachment anxiety. Journal of personality and social psychology 2005;88:510-531. [PubMed: 15740443]

47. Gottman MJ, Krokoff LJ. Martial interaction and satisfaction: A longitudinal view. Journal of consulting and clinical psychology 1989;57:47-52. [PubMed: 2487031]

48. Fredrickson BL. The broaden-and-build theory of positive emotions. Philos Trans R Soc Lond B Biol Sci 2004;359:1367-1378. [PubMed: 15347528] 
49. Ayduk O, Zayas V, Downey G, Cole AB, Shoda Y, Mischel W. Rejection Sensitivity and Executive Control: Joint predictors of Borderline Personality features. J Res Pers 2008;42:151168. [PubMed: 18496604]

50. Buckner JC, Mezzacappa E, Beardslee WR. Characteristics of resilient youths living in poverty: the role of self-regulatory processes. Development and psychopathology 2003;15:139-162. [PubMed: 12848439]

51. Hooley JM, Gruber SA, Scott LA, Hiller JB, Yurgelun-Todd DA. Activation in dorsolateral prefrontal cortex in response to maternal criticism and praise in recovered depressed and healthy control participants. Biological psychiatry 2005;57:809-812. [PubMed: 15820239]

52. Hooley JM, Gruber SA, Parker HA, Guillaumot J, Rogowska J, Yurgelun-Todd DA. Corticolimbic response to personally challenging emotional stimuli after complete recovery from depression. Psychiatry research 2009;172:83-91. [PubMed: 19452633] 


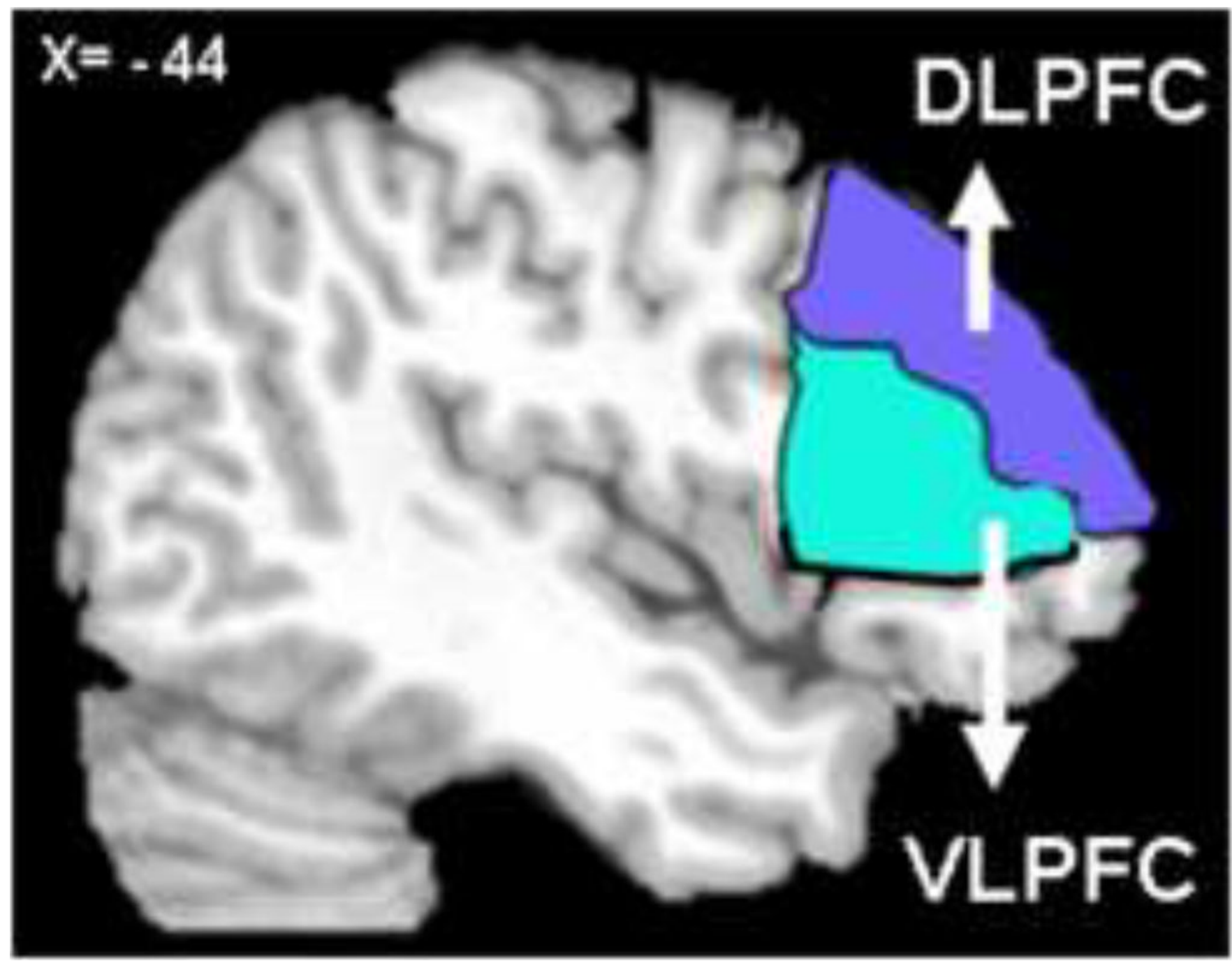

Figure 1.

shows the anatomical mask used to identify lateral prefrontal cortex (LPFC) activity. Significant activity in the whole-brain, random effects analysis that was within this LPFC region of interest was identified (listed in Table2) and then individual contrast values were extracted. The LPFC anatomical mask included the ventral portion (VLPFC) shown in light blue and dorsal portion (DLPFC) shown in dark blue. The VLPFC included the inferior frontal gyrus -triangularis [BA 45, and portions of BA 44). The DLPFC included the middle frontal gyrus [portions of BA 46, BA 9, and BA10]. The LPFC mask was created by using the Automated Anatomical Labeling (AAL) maps in the program MRIcro (http://www.sph.sc.edu/comd/rorden/template.html) as a guide for identifying the inferior frontal and middle frontal gyri and the Brodmann's Areas. 


\section{A. Partner Negative vs. Partner Neutral}

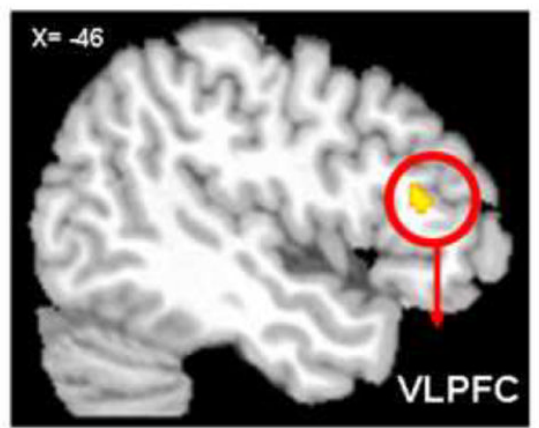

D. VLPFC predicts substance-use after conflict

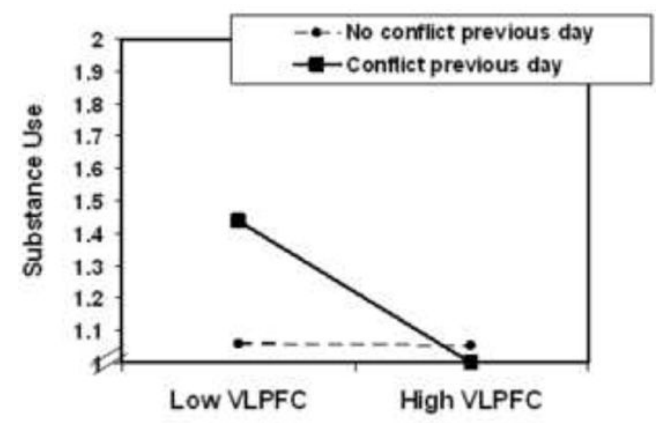

B. VLPFC predicts overall negative mood after conflict

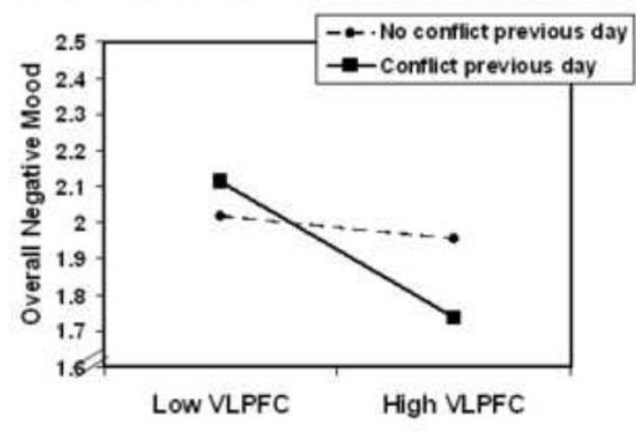

C. VLPFC predicts rumination after conflict

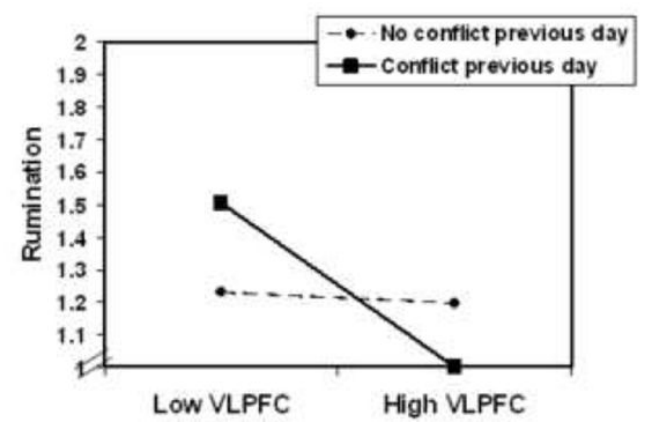

Figure 2.

A. Whole-brain, random-effects analysis across the group of subjects $(\mathrm{N}=27)$ shows significant left VLPFC activity for Partner Negative vs. Partner Neutral expressions contrast. B. Individual level of VLPFC activity, extracted from this group activation, significantly interacted with interpersonal conflict to predict overall negative mood. Higher scores correspond to more negative mood (graphed on the Y-axis). As shown in the figure, when there was no conflict the previous day, VLPFC activity was not related to overall negative mood. However, when a conflict occurred the previous day, lower VLPFC activity was related to more overall negative mood. The same pattern of results can be seen with $\mathbf{C}$. rumination, and D. substance-use. 


\section{A. Partner Positive vs. Partner Neutral}

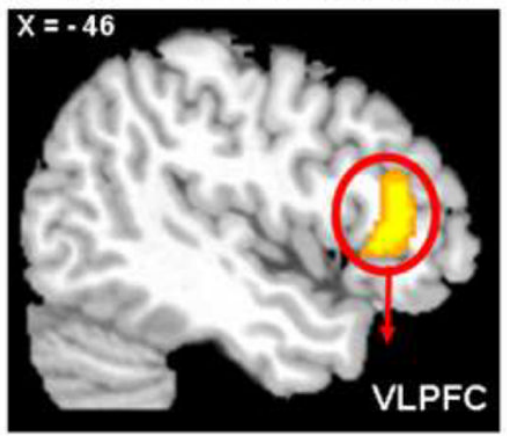

\section{B. VLPFC predicts overall negative mood after conflict}

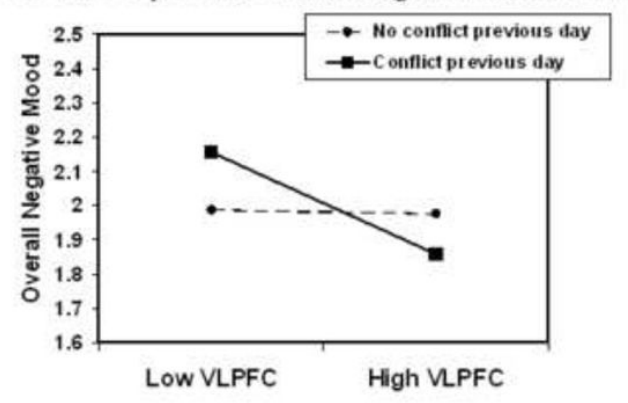

Figure 3.

A. Whole-brain, random-effects analysis across the group of subjects $(\mathrm{N}=27)$ shows significant left VLPFC activity for Partner Positive vs. Partner Neutral expressions. B. Individual level of VLPFC activity, extracted from this group activation, significantly interacted with interpersonal conflict to predict overall negative mood. On days in which there was no conflict the previous day, VLPFC activity was not related to overall negative mood. On days in which there was a conflict the previous day, VLPFC activity significantly predicted overall negative mood, such that lower VLPFC activity was related to more overall negative mood. 


\section{Table 1}

Behavioral ratings in response to the question, "How does this picture make you feel? $[1=$ very negative, $2=$ slightly negative, $3=$ slightly positive, $4=$ very positive]. Ratings listed as group mean [X (Standard Deviation)]. Paired t-tests show differences between conditions.

\begin{tabular}{|l|l|l|l|}
\hline Partner Conditions & Rating & Stranger Conditions & Rating \\
\hline Partner Negative & $1.8(.27)$ & Stranger Negative & $1.7(.24)$ \\
\hline Partner Positive & $3.5(.27)$ & Stranger Positive & $3.2(.46)$ \\
\hline Partner Neutral & $2.6(.47)$ & Stranger Neutral & $2.4(.38)$ \\
\hline \multicolumn{2}{|c|}{ Paired t-tests of Ratings for Different Conditions } \\
\hline Partner Negative vs. Partner Neutral & $t=10.6^{* *}$ & Stranger Negative vs. Stranger Neutral & $t=9.8^{* *}$ \\
\hline $\begin{array}{l}\text { Partner Positive vs. Partner Neutral } \\
\text { Partner Negative vs. Stranger Negative }\end{array}$ & $t=7.5^{* *}$ & Stranger Positive vs. Stranger Neutral & $t=7.4^{* *}$ \\
\hline $\begin{array}{l}* * \\
p<.001\end{array}$ & Partner Positive vs. Stranger Positive & $t=3.1^{*}$ \\
\hline \\
$\begin{array}{l}* \\
p<.01\end{array}$
\end{tabular}


苋的泀

号要 $\frac{2}{0}$

.

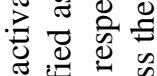

UT

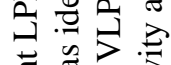

䒕芯范

: 爷元

严造造

\begin{tabular}{|c|c|c|c|c|c|c|c|c|c|}
\hline 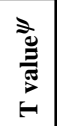 & $\begin{array}{l}\vec{\infty} \\
\stackrel{r}{~}\end{array}$ & के & Oో. & 芦 & $\begin{array}{l}\text { ปิ } \\
\dot{+}\end{array}$ & $\begin{array}{l}0 \\
\dot{m}\end{array}$ & $\mid \begin{array}{l}0 \\
\text { లె }\end{array}$ & 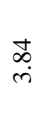 & 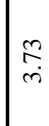 \\
\hline 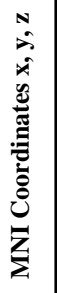 & $\mid \begin{array}{c}0 \\
\stackrel{1}{0} \\
\infty \\
\sim \\
\dot{+} \\
i \\
1\end{array}$ & $\begin{array}{l}\sim \\
\dot{p} \\
\dot{p} \\
\dot{p} \\
\dot{1}\end{array}$ & 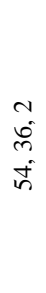 & 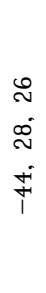 & 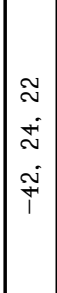 & 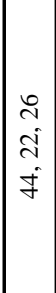 & 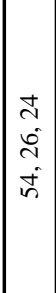 & $\begin{array}{l}\dot{ } \\
\infty \\
\infty \\
\dot{f}\end{array}$ & $\mid \begin{array}{l}0 \\
\text { iे } \\
\dot{m} \\
\dot{+} \\
\dot{i}\end{array}$ \\
\hline 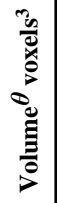 & $\simeq$ & is & $\Sigma$ & $m$ & in & in & \pm & $=$ & $\infty$ \\
\hline$\widehat{\Phi}$ & if & $\stackrel{\wp}{r}$ & rq & rq & if & $\begin{array}{l}q \\
\dot{f} \\
\dot{f}\end{array}$ & if & ig & r \\
\hline 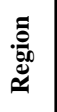 & $\mid \begin{array}{l}0 \\
0 \\
0 \\
\\
\end{array}$ & $\begin{array}{l}0 \\
\\
\\
\\
\end{array}$ & 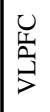 & 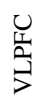 & 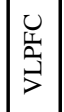 & 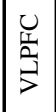 & 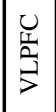 & 炛 & \begin{tabular}{|l}
0 \\
0 \\
\\
\\
\end{tabular} \\
\hline$\stackrel{\vec{z}}{\underline{2}}$ & نـ & نـ & $\propto$ & نــ & ن. & $\propto$ & $\propto$ & $\propto$ & نــ \\
\hline 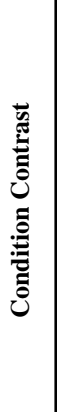 & 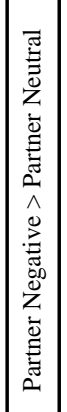 & 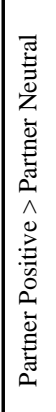 & : & 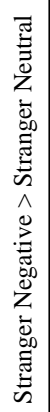 & 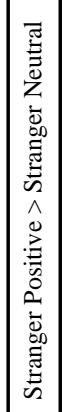 & & : & 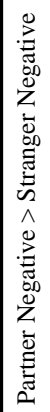 & 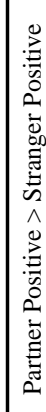 \\
\hline
\end{tabular}

宛完

范品

它

8 II 0 吾 造过志造

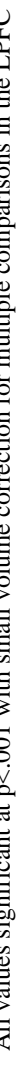

